\title{
Lovecraft e Poe: ressonâncias nos contos dos mestres do horror e suas criações de sensações e ambiências ${ }^{1}$
}

\author{
Yuri Garcia \\ Universidade Estácio de Sá
}

\section{Resumo}

O presente trabalho tem por objetivo apresentar similaridades entre dois grandes nomes da literatura de horror, Edgar Allan Poe e H. P. Lovecraft. O segundo mantinha correspondências e diários de sua vida pessoal, além de ter escrito ensaios sobre o gênero, de forma que podemos perceber a idolatria que possuía por seu antecessor registrada com suas próprias palavras. Assim, destacaremos algumas similaridades a fim de apontar um conto mais desconhecido de Poe como, possivelmente, uma das maiores inspirações dentro de sua obra para o desenvolvimento da narrativa e da mitologia criada por seu precursor. Entre os pontos importantes de interseção que percebemos, destacamos aqui para uma breve análise: a investigação ou relato de experiência testemunhada do narrador, a atmosfera criada para o conto de horror e o perigo oriundo dos mares e oceanos.

\section{Palavras-chave}

Lovecraft; Edgar Allan Poe; Horror; Comunicação; Literatura.

\section{Introdução}

Em 1963, o diretor Roger Corman, famoso por suas parcerias com o ator Vincent Price e pelas inúmeras versões cinematográficas de contos de Edgar Alan Poe, realizou o filme Edgar Allan Poe's The Haunted Palace, lançado no Brasil como O Castelo Assombrado. A princípio, essa poderia parecer mais uma das investidas da dupla Corman/Price em um filme de mistério e horror baseado nas obras de Poe, mas tratava-se, na verdade, de algo mais complicado, e que talvez até hoje não seja possível compreender inteiramente.

Com uma chamada que remetia diretamente ao autor Edgar Allan Poe's The Haunted Palace (algo parecido com o que Francis Ford Coppola fez em seu filme Dracula, de 1992, e que foi até incorporado em sua tradução para o título bra-

1 Uma versão inicial deste trabalho foi apresentada e originalmente publicada nos Anais do $5^{\circ}$ Encontro Comunicom de 2015.

Revista Ícone (ISSN 2175-215X) • DOI: 10.34176/icone.v17i3.240541

Recife, Vol. 17, N. 3, 302-318, ๑ 2019 PPGCOM/UFPE.

Artigo recebido em 6 abr. 2019 e aprovado em 12 ago. 2019.

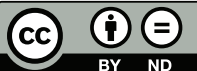


sileiro como Drácula de Bram Stoker), é curioso descobrir que o filme de Corman não trata de um conto de Poe, e sim de um conto de Lovecraft.

A película é baseada no conto O Caso de Charles Dexter Ward, escrito em 1927, porém publicado apenas em 1941, após a morte do autor. O filme se enquadra nos moldes de diversas outras produções feitas pela parceria Corman/Price, e é considerado ainda um bom filme de horror (com uma nota 6,8 no internet movie database $^{2}$ e $71 \%$ de aprovação no Rotten Tomatoes ${ }^{3}$, dois dos principais sites de filmes da internet). Além de ter sido vendida como mais uma adaptação de uma obra de Edgar Alan Poe, é até hoje assim conhecida, mesmo em um momento no qual Lovecraft vem sendo cada vez mais consumido e conhecido pela chamada cultura de massa ${ }^{4}$.

Mas o que poderia ter motivado essa decisão de atribuir a fonte literária do filme a Poe? Por que alimentar tal farsa? Por que vender dessa forma um produto que poderia ser facilmente desmascarado? E por que a insistência em manter isso mesmo hoje, momento em que Lovecraft tem recebido seu devido reconhecimento por seu talento? Talvez algumas dessas perguntas sem respostas apenas acrescentem algo ao ar de estranheza do universo lovecraftiano. Todavia, o que se sabe é que a decisão veio da produtora American International Pictures. contra a vontade do diretor e também produtor Roger Corman, conforme o próprio relata em uma entrevista a Andrew Migliore e John Strysik no livro Lurker in the Lobby: A guide to the cinema of H. P. Lovecraft (2006, p.204).

Podemos levantar uma possibilidade de que a AIP não quisesse associar o nome do filme ao de Lovecraft em uma época em que ele não possuía o mesmo prestígio de hoje. Ou, segundo Corman destaca em sua entrevista, apenas por questões financeiras, para aproveitar o sucesso da sequência de transposições de contos de Poe que haviam produzido (p.205). Ainda assim, tal fato, pode nos chamar a atenção para a confusão entre as obras de Poe e Lovecraft e algumas questões de autoria e influência de um autor em outro que iremos investigar.

Dentro da ampla obra de Poe, um conto específico possui similaridades interessantes, aparentando (sem um olhar mais atento) até ter sido inspirado em Lovecraft. No entanto, Edgar Allan Poe nasceu em 1809 e morreu em 1849, tendo escrito seu conto Uma Descida no Maelstrom (A Descent into the Maelström no original em inglês) no ano de 1841, 49 anos antes do nascimento de Lovecraft.

Contudo, a peculiaridade de um conto de Poe possuir um aspecto lovecraftiano intriga, não apenas pelo fato de poder perceber nele uma possível (senão provável) inspiração para Lovecraft, mas também pela estranheza que tal afirmação provoca. A questão é que se trata de um conto de Poe pouco conhecido e também um pouco diferente do que o autor costuma nos oferecer, mas que se parece

2 http://www.imdb.com

3 http://www.rottentomatoes.com

4 Destacamos já, desde o início do trabalho, que não desejamos cair em dicotomias como cultura de massa e cultura erudita. Qualquer utilização no texto servirá apenas como um operador teórico. 
muito com o que Lovecraft faz na extensão de sua obra. Assim, acabamos remetendo as características de um ao outro, independente do claro problema cronológico que isso traz.

Aqui cabe lembrar a teoria desenvolvida por Harold Bloom em A Angústia da Influência (2002), no qual é apresentado o sentimento de escritores que se inspiram em seus precursores, sentindo a necessidade de superar suas obras. Segundo Bloom, todo autor tardio (belated) sente o peso de seus precursores e assim se vê obrigado a confrontar-se com sua obra deslendo-a (misreading) e reelaborando-a. Este trabalho procura encontrar algumas interseções entre ambos os autores e destacar o conto apontado acima como um possível inspirador para a elaboração do Cthulhu Mythos, a mitologia cósmica criada por Lovecraft em seu universo literário.

\section{Lovecraft e Poe}

Edgar Allan Poe nasceu em 1809 e ainda criança ficou órfão ao perder sua mãe, que morrera pouco após seu pai ter abandonado a família. Ele então foi adotado (embora não formalmente) pelo casal Francis Allan e John Allan. Sua vida foi repleta de complicações financeiras por ter sido um dos primeiros escritores estadunidenses (o primeiro entre os nomes mais conhecidos) a tentar ganhar a vida apenas através da atividade literária. Poe fez parte do movimento romântico e ficou conhecido por suas histórias que envolviam o misterioso e o macabro, além de ter sido também um dos primeiros escritores americanos de contos curtos.

Poe é considerado por alguns teóricos literários, como Tzvetan Todorov, como o inventor do gênero ficção policial. Segundo Todorov, "Poe deu origem à novela policial contemporânea, e esta cercania não é fruto da casualidade; frequentemente se afirma, por outro lado, que os contos policiais substituíram os contos de fantasmas" (2012, p.27). Além disso, também recebe importante crédito por sua contribuição ao então emergente gênero de ficção científica - que veio a ser uma das áreas exploradas com frequência por Lovecraft. Contudo, os críticos de sua época não o viam com a mesma admiração que seu público, como revela Paes.

De qualquer modo, o público não subscreveu a opinião da crítica. Edgar Allan Poe continua sendo escritor prestigiado pelo leitor comum, que ainda se encanta com suas histórias de terror. E talvez esse despretensioso leitor esteja com a razão, pois, a despeito da linguagem "glutinosa" ou do estilo "mecânico", Poe sempre consegue, em mais de um momento, provocar-nos aquele arrepio de morte ou aquela impressão de vida que, em literatura, constituem o melhor, senão o único, passaporte para a imortalidade. (PAES em: POE, 2008, p.10-11) ${ }^{5}$

5 Apresentação da edição de 2008 do livro Histórias Extraordinárias traduzido por José Paulo Paes. 
Em 20 de Agosto de 1890, na cidade de Providence, Rhode Island, EUA, nascia Howard Philips Lovecraft. Com um intelecto que parecia atuar no limite entre a genialidade e a loucura, como apontado em sua interessante biografia ${ }^{6}$, e com uma enorme dificuldade para conseguir encontrar empregos estáveis ou sustentar-se através de sua escrita, o autor viveu uma vida publicando seus contos em revistas amadoras. Morreu em 15 de Março de 1937, precisamente no momento em que parecia atingir sua maturidade intelectual e literária, ensaiando um início de reconhecimento que apontava para seu possível ápice como escritor.

Lovecraft não foi um autor de grande repercussão ou sucesso em vida. Mesmo assim, possuía fiéis seguidores de seu trabalho, que contribuíram para fazer algumas de suas últimas obras chegarem às prensas. Não muito tempo após sua morte, as histórias do autor começam a se firmar no cenário da literatura de horror, destacando-o como um dos principais nomes do gênero e conquistando legiões cada vez maiores de admiradores entre nichos de públicos específicos. Atualmente, está consolidado como um grande nome do horror e da ficção fantástica, e sua mitologia e suas perspectivas foram incorporadas em nossa cultura, sendo continuamente reelaboradas. Lovecraft é tão conhecido hoje, que até mesmo em espaços como a Wikipedia brasileira, podem-se encontrar bons textos sobre sua obra, conforme o verbete citado a seguir:

O princípio literário de Lovecraft era o que ele chamava de "Cosmicismo" ou "Terror Cósmico", que se resume à ideia de que a vida é incompreensível ao ser humano, e de que o universo é infinitamente hostil aos interesses do homem. Isto posto, as suas obras expressam uma profunda indiferença às crenças e atividades humanas. (Wikipédia) $^{7}$

O verbete citado oferece uma breve, porém eficiente descrição do princípio literário das obras de Lovecraft. Na realidade, embora a mitologia lovecraftiana seja um pouco complexa, é interessante como encontramos diversas explicações satisfatórias ao procuramos na internet em meios mais simples de pesquisa como este.

Lovecraft nos apresenta seres indescritíveis e cria universos que ultrapassam os limites da racionalidade. Seu mundo imaginário representa o ser humano como criatura abandonada em um cosmos indiferente à sua existência, dando forma a uma peculiar mitologia não-antropocêntrica (ou mesmo anti-antropocêntrica). Em seu universo de ficção, espécies alienígenas muito superiores teriam dominado a Terra em um passado remoto e aguardam adormecidas seu retorno

6 Para mais detalhes ver o livro de S. T. Joshi A Dreamer and a Visionary: H. P. Lovecraft in his time (2001) ou sua tradução em português de 2014 A Vida de H. P. Lovecraft.

7 https://pt.wikipedia.org/wiki/H._P._Lovecraft 
em um futuro apocalíptico ${ }^{8}$. Dessa forma, o autor nos apresentou um conceito de divindade que prescinde dos homens, e que habita outras dimensões, com noções de tempo e de espaço que vão além da capacidade da compreensão humana. Essa mitologia construída por Lovecraft evoca uma religiosidade monstruosa de alienígenas, e também uma perspectiva do ser-humano como insignificante diante de um cosmos que aponta para o imenso poder do Desconhecido.

Se olharmos apenas por essa perspectiva que vimos apresentando, não há tanto em comum entre os autores a não ser o gênero do horror. No entanto, Lovecraft foi um grande admirador de Poe, e em diversas de suas cartas e textos, revela ter-se inspirado imensamente em sua obra. Em seu famoso texto Supernatural Horror in Literature (1927), Lovecraft dedicou a sétima parte do ensaio exclusivamente a Poe. E, na oitava parte, intitulada The Weird Tradition in America, o nome do escritor aparece novamente inúmeras vezes como figura de destaque.

Lovecraft era não apenas um grande admirador, mas também um profundo conhecedor das obras de Poe, sendo considerado por alguns teóricos, como Paul Buhle, como seu principal herdeiro. Uma importante característica dos contos lovecraftianos são seus desfechos pessmistas e sombrios. Tal característica é uma importante herança de Poe, que também apresentava finais sombrios para seus contos, com seus personagens presos, assassinados ou deprimidos. Como descreve Buhle, "Lovecraft era uma profunda cria de Poe, e um dos mais sérios acadêmicos a estudar a obra do escritor em uma época em que, na alta cultura da América, sua reputação havia alcançado um declínio." (BUHLE, 1976, p.122) ${ }^{9}$

Lovecraft foi um grande admirador das obras de Poe desde sua solitária infância, dentro da biblioteca de sua casa. Relacionar os escritos de um com o outro é sempre um passo lógico quando se trata de discutir as inspirações lovecraftianas. Não é incomum, também, vermos o único romance de Poe, $A$ Narrativa de Arthur Gordon Pym (1938) sendo comparada a Lovecraft, devido à utilização da Antártida como cenário de eventos misteriosos e inexplicáveis. No entanto, aqui pretendemos sair dessas observações gerais. Dentro da amplitude das obras de Poe, destacamos um conto específico, por apresentar algumas características encontradas na mitologia de Lovecraft, e que pode ter sido uma importante influência na criação do Cthulhu Mythos.

O conto Uma Descida no Maelstrom, escrito por Edgar Allan Poe em 1841, A história é inspirada no fenômeno natural do Moskstraumen, um tipo de redemoinho formado junto ao arquipélago de Lofoten, na costa da Noruega. A narração é feita por um relato dentro de um relato, isto é, uma história dentro de uma

8 Nesse sentido, é possível especular que seu impacto na cultura contemporânea (por exemplo, em formas de literatura esotérica popular ou na vertente de Eram os Deuses Astronautas, de Erik Von Däniken) foi ainda maior do que se poderia pressupor à primeira vista. Ver a curiosa tese de Jason Colavito em The Cult of Ancient Gods: H. P. Lovecraft and Extraterrestrial Pop Culture (2005).

9 Todas as traduções do texto, quando não apontadas o contrário, serão de nossa autoria: "Lovecraft was the profound child of Poe, and one of the most serious scholars of that writer in a time when, in the High Culture of America, his reputation had gone into a decline." (p.122) 
história. Um ouvinte contando a experiência que lhe foi narrada por outra pessoa.

Na história, um homem e seus dois irmãos são apanhados por um furacão enquanto pescavam e seu barco é conduzido ao centro de um poderoso redemoinho, de onde não conseguem sair. Assim, são puxados para dentro do redemoinho e, cada vez mais, para baixo, esperando o terrível destino que os reserva de serem engolidos pela fúria da natureza. Durante o evento, o homem testemunha a morte de um de seus irmãos e, ao final, abandona o outro para um destino similar, no intuito de conseguir se salvar. O Maelstrom, então, é descrito como o horror que os conduzia para a morte. Entretanto, ao longo da narrativa, vemos uma mudança na descrição, quando passa a ser caracterizado também por sua beleza, grandiosidade, e como um maravilhoso espetáculo que mostra a força extraordinária da natureza.

Nesse conto de Poe, destacado acima, o oceano traz o desconhecido, o espantoso, o perigo de morte, e nos mostra o ser humano insignificante diante da potência do Maelstrom.

Não se trata de uma história muito conhecida do autor, e de fato, foge um pouco dos assuntos típicos de suas outras obras - porém, um leitor ávido como Lovecraft conheceria bem Uma Descida no Maelstrom.

Embora os estilos de escrita de ambos os autores possuíssem algumas características em comum, esse conto traz elementos não muito conhecidos de Poe que acreditamos que tenham sido importantes para Lovecraft. Procuramos analisar alguns aspectos em comum entres os dois escritores e destacar um pouco o que mais desperta nosso interesse em Uma Descida no Maelstrom. Aqui, gostaríamos de destacar uma perspectiva sobre a narração do protagonista-investigador e a importância do olhar na obra dos dois autores. Mais adiante, retornaremos ao Maelstrom de Poe e suas ressonâncias com a visão de mundo lovecfratiana.

O relato de uma experiência pavorosa - isto é, ter visto e presenciado algo -, a investigação detetivesca e a pulsão escópica são aspectos importantes nas histórias de ambos os autores. Como já dissemos, Poe foi um dos precursores dos romances policiais, e, com o detetive fictício C. Auguste Dupin, esse gênero rapidamente adquiriu popularidade entre as massas. O investigador é um ser curioso, alguém cujos olhos devem ser saciados pela necessidade de testemunho. Tom Gunning destaca a relação entre detetives e investigações policiais com o visual para reconhecer suspeitos por meio da validade da fotografia como registro e catalogação de criminosos em seu ensaio $O$ retrato do corpo humano: a fotografia, os detetives e o primórdio do cinema (2004). O gênero literário gótico já trabalhava o desvendamento de um mistério em histórias mais voltadas para o horror, e tanto Poe como Lovecraft se utilizaram de tal ferramenta em suas narrativas. Herbert Marshall McLuhan ${ }^{10}$ apontava a invenção da prensa trazendo uma ruptura entre tradição oral e tradição visual; em outra perspectiva, Jonathan Crary propõe em

10 Para mais detalhes ver: A Galáxia de Gutenberg (1977) e Os Meios de Comunicação como Extensões do Homem (2007). 
seu livro Técnicas do Observador (2012) que tal ruptura ocorre em torno de 1820, época de grande popularização da literatura gótica.

No início do século XIX, a ruptura com os modelos
clássicos de visão foi muito mais do que uma simples
mudança na aparência das imagens e das obras de arte,
ou nas convenções de representação. Ao contrário, ela
foi inseparável de uma vasta reorganização do conheci-
mento e das práticas sociais que, de inúmeras maneiras,
modificaram as capacidades produtivas, cognitivas e de-
sejantes do sujeito humano. (p.13)

Segundo Crary, novas tecnologias que ofereciam um lugar de destaque para o olho começavam a surgir, novas ciências e perspectivas de estudo do olho humano, e a ideia de sujeito se reformulava.

A partir do início do século XIX, com Goethe, e já nas décadas de 20 e 30 do século XIX, com o desenvolvimento de novas ciências empíricas (sobretudo a fisiologia óptica e a psicofisiologia), o olho mergulha na opacidade e na espessura do corpo humano, com sua inevitável contingência e sua variabilidade incontrolável. (FERRAZ, 2010, p.27)

Pelo prisma McLuhaniano, tal período ainda estaria imerso no momento em que o teórico canadense denomina Galáxia de Gutenberg, e podemos destacar qualquer texto pós-invenção da prensa como produto de uma sociedade visual. Pela perspectiva de Crary, que traz instrumentos tecnológicos e ciências surgidas no início do século XIX como importantes para a maior valorização da visão, os dois escritores também estariam vivenciando tais mudanças que moldavam a sociedade e atribuíam ao olho um protagonismo entre os sentidos.

Não pretendemos nos apoiar nesses teóricos para elencar os escritores como produtos sintomáticos de uma época com predomínio exacerbado de um sentido, e a menção aqui de suas perspectivas é apenas para demonstrar possíveis caminhos de reflexão. Aqui, procuramos apenas destacar a importância do olhar e do descobrimento visual em contos que contam com relatos de testemunhas oculares dos eventos pavorosos. Evitando adotar uma postura mais globalizante como McLuhan e Crary, podemos destacar com mais firmeza apenas uma inspiração do romance gótico e da literatura policial iniciada com Poe. De qualquer forma, a curiosidade e a necessidade de comprovar através da visão são bases que servem como fios condutores dos contos de Poe e Lovecraft.

Em Poe, essa característica é apresentada de forma mais objetiva, rumo ao descobrimento de um responsável por mortes ou outros tipos de crimes - como normalmente visto nas narrativas de suspense e horror - ou das formas mais va- 
riadas possíveis como em contos como O Homem da Multidão (1840) ou narrativas que flertam mais com o sobrenatural. Uma Descida no Maelstrom, assim como as histórias de Lovecraft revelam a possibilidade de conhecer um mundo misterioso, não necessariamente bom ou ruim, em nosso próprio planeta. Nesse caso, mais especificamente, mostrando-nos a fúria e a potência da natureza nos mares e oceanos.

Desde o século XVI, as grandes navegações e os avanços científicos acabaram deixando o desconhecido apenas para outros planetas e o espaço sideral. A frase "Space, the final frontier" dos seriados e filmes da franquia Star Trek é sintomática desse fato. De certo modo, acabamos perdendo parte do mistério do nosso planeta, que costumava ser atribuído aos mares e oceanos. Podemos perceber uma longa tradição de seres míticos aquáticos como o Leviatã, o monstro do lago Ness, o Cracken e outros. Os mares e oceanos se mostravam como uma enorme porção do nosso mundo que era inexplorada pela humanidade, e onde figuravam temores e superstições dos homens. Lovecraft, em sua obra, retoma a ideia do desconhecido como algo que habita o mesmo plano que nós, apontando para a nossa cegueira e ignorância sobre a verdade como fundamentais para nossa felicidade e sanidade no mundo. Não é casual, portanto, o fato de que vários seres da mitologia de Cthulhu habitem as profundezas aquáticas.

Outro importante aspecto visto nas obras de Poe (e talvez, sobretudo, em Uma Descida no Maelstrom) que podemos perceber é a atmosfera de horror construída.

Relativamente ao conto, as ideias de Poe não se afastam das suas demais ideias sobre o fato artístico em geral. Preconizava, nesse gênero, o uso e abuso do que denominava "a unidade de efeitos". Ao descrever uma short story, devia o artista ter sempre em mente o desfecho da narrativa e, de acordo com esse desfecho, dispor as cenas, criar a atmosfera, de modo a provocar no leitor um efeito definido de enternecimento, de solidão, de horror etc. (PAES em: POE, p.10, grifo nosso) ${ }^{11}$

A seguir, podemos ver nas palavras do próprio Lovecraft, a mesma preocupação:

Meu motivo para escrever histórias é dar a mim mesmo a satisfação de visualizar mais claramente e detalhadamente e consistentemente as vagas, elusivas, fragmentárias impressões de maravilha, beleza e expectativa aventureira que são transmitidas pra mim por certas expectativas (cênica, arquitetural, atmosférica, etc.), ideias, ocorrências e imagens encontradas na arte e literatura.

11 Apresentação da edição de 2008 do livro Histórias Extraordinárias traduzido por José Paulo Paes. 
(LOVECRAFT, grifo nosso) 12

O autor alemão Hans Ulrich Gumbrecht desenvolveu o conceito de Stimmung a fim de destacar melhor a ideia das sensações e ambiências causadas pela leitura (e que se exemplifica perfeitamente, aqui, na sensação de ler Lovecraft e Poe). Infelizmente, tal palavra alemã não possui uma tradução para o português que consiga trazer todas as possibilidades que Gumbrecht sugere. Entre suas traduções mais comuns, podemos citar os termos ambiência e atmosfera. O texto Reading for the Stimmung? About the Ontology of Literature Today (2008) de Gumbrecht apresenta uma explicação detalhada de tal conceito.

Segundo o autor, um texto não provoca apenas processos de compreensão, interpretação e análise do conteúdo escrito por uma perspectiva puramente hermenêutica ${ }^{13}$, mas também nos abala de uma forma sensorial. Em casos como a poesia percebemos isso de forma mais clara, mas o conto de horror também dialoga com essa necessidade sensorial para envolver o leitor, e Lovecraft e Poe sempre foram autores que se dedicaram com entusiasmo à criação de tais sensações ou ambiências.

Ao narrar uma descida no redemoinho dentro do mar, Poe se vale da produção de um efeito/afeto a partir da convocação de cenários e situações que beiram o insólito para o espectador/leitor. Aqui, em uma passagem do conto de Poe, a sensação e os afetos claramente criam a atmosfera necessária ao horror: "Não vou esquecer nunca as sensações de medo, horror, e admiração pelo que pude olhar a minha volta". ${ }^{14}$ Com Lovecraft, talvez tal característica se acentue mais, uma vez que a imprecisão das descrições de seus seres se mistura com um paradoxal excesso de adjetivos ao fazê-lo, de forma que, no resultado final, a sensação de não saber, ou melhor, de não compreender a dimensão do que estamos tentando descobrir nos causa maior assombro, como podemos ver na descrição de seu mais famoso ser, Cthulhu, no conto The Call of Cthulhu:

Representava um monstro de estrutura vaamente antropóide, mas com uma cabeça similar a um polvo, cujo rosto era uma massa de palpos, um corpo escamoso, de aparência gomosa, garras prodigiosas atrás e na frente dos pés, e asas longas e estreitas atrás. Esta coisa, que parecia instintiva com uma malignidade temível e não natural, era de uma corpulência um tanto inchada, e agachava-se malignamente em um bloco retangular ou

12 "My reason for writing stories is to give myself the satisfaction of visualizing more clearly and detaidedly and stably the vague, elusive, fragmentary impressions of wonder, beauty and adventurous expectancy which are conveyed to me by certain sights (scenic, architectural, atmospheric, etc.), ideas, occurences and images encountered in art and literature." (LOVECRAFT)

13 Embora o termo seja bem amplo, usá-lo-ei de acordo com a perspectiva que o próprio autor utiliza, sobretudo em sua famosa obra Produção de presença: o que o sentido não consegue transmitir. (2010)

14 "Never shall I forget the sensations of awe, horror, and admiration with which I gazed about me." (POE) 
pedestal coberto com caracteres indecifráveis. As pontas das asas tocavam a borda de trás do bloco, o assento ocupava o centro, enquanto as longas e curvas garras das patas traseiras dobradas, agachadas agarraram a borda dianteira e estenderam um quarto do caminho para baixo em direção ao fundo do pedestal. A cabeça do cefalópode estava dobrada para a frente, de modo que as extremidades dos palpos faciais escovassem as costas de enormes patas dianteiras que apertavam os joelhos elevados do agachado. (LOVECRAFT) ${ }^{15}$

No ensaio Supernatural Horror in Literature (1927), escrito por Lovecraft, o escritor destacava a importância da questão: "Atmosfera é o mais importante, pois o critério final de autenticidade não é recorrente de uma trama e sim a criação de uma determinada sensação." ${ }^{16}$ (p.5)

Tais efeitos são alcançados devido às suas complexas descrições de seres com monstruosidades de difícil compreensão, com hibridações incoerentes, causando-nos certo mal estar, em uma estratégia típica do gênero horror, como aponta Carrol, para quem: "O Horror é um gênero predicado em explorar nossa fascinação com o feio, o anômalo, e a categoria de violação." ${ }^{17}$ (CARROLL, 2003, p.92). Os corpos descritos por Lovecraft se encontram em uma impossibilidade imaginária que faz com que não se enquadrem nem no conceito de utopia, nem de heterotopia $^{18}$ conforme descrita por Foucault. Parece ser algo além, algo que flerta com o distópico e com um desejo de aniquilação, ou com o irrepresentável ${ }^{19}$.

Entretanto, o conceito foucaultiano apontado acima se aplica com facilidade aos espaços que o escritor descreve em suas narrativas. Para Foucault, uma utopia é uma ideia ou imagem que não possui um correspondente verdadeiro, mas

15 "It represented a monster of vaguely anthropoid outline, but with an octopus-like head whose face was a mass of feelers, a scaly, rubbery-looking body, prodigious claws on hind and fore feet, and long, narrow wings behind. This thing, which seemed instinct with a fearsome and unnatural malignancy, was of a somewhat bloated corpulence, and squatted evilly on a rectangular block or pedestal covered with undecipherable characters. The tips of the wings touched the back edge of the block, the seat occupied the centre, whilst the long, curved claws of the doubled-up, crouching hind legs gripped the front edge and extended a quarter of the way down toward the bottom of the pedestal. The cephalopod head was bent forward, so that the ends of the facial feelers brushed the backs of huge fore paws which clasped the croucher's elevated knees." (LOVECRAFT)

16 "Atmosphere is the all-important thing, for the final criterion of authenticity is not the dovetailing of a plot but the creation of a given sensation." (LOVECRAFT, 1927, p.5)

17 "Horror is a genre predicated on exploring our fascination with the ugly, the anomalous, and the category of violation." (CARROLL, 2003, p.92)

18 Ver: Outros Espaços (2006) e O Corpo Utópico, As Heterotopias (2013).

19 A ideia de algo "irrepresentável" em uma sociedade dominada por imagens é assunto digno de um grande e talvez inconclusivo debate filosófico. Jacques Rancière destina um capítulo de seu livro O Destino das Imagens (2012) para problematizar se o Irrepresentável existe, ou melhor, em que condições existiria. 
trata de uma projeção ou criação aperfeiçoada de algo. As heterotopias seriam espaços que têm diversas camadas de significação ou de relações a outros lugares com complexidades que não podem ser vistas sem uma análise mais profunda.

É aí, sem dúvida, que encontramos o que de mais essencial existe nas heterotopias. Elas são a contestação que pode ser exercida de duas maneiras: ou como nas casas de tolerância de que Aragon falava, criando uma ilusão, ou, ao contrário, criando outro espaço real tão perfeito, tão meticuloso, tão bem disposto quanto o nosso é desordenado, mal posto e desarranjado; é como este último que funcionaram, ao menos no projeto dos homens, durante algum tempo - principalmente no século XVIII - as colônias. (FOUCAULT, 2013, p.28)

Lovecraft promove uma complexa mitologia que envolve descrições arquitetônicas de cidades perdidas e divinas que atravessam nossas noções de espaço-tempo.

Sem saber o que é o futurismo, Johansen alcançou algo muito próximo quando falou da cidade; pois, ao invés de descrever qualquer estrutura ou construção definitiva, ele se baseia apenas em impressões amplas de grandes ângulos e superfícies de pedra - superfícies muito grandes para pertencer a qualquer coisa correta ou característica dessa terra e com ímpias imagens horríveis e hieróglifos. (LOVECRAFT, 2011) ${ }^{20}$

Esse pequeno trecho do conto de Lovecraft acima nos mostra a dificuldade em conseguir assimilar os espaços que o autor descreve. Tal complexidade se encontra com a ideia de Foucault, ao passo que: "É a incronguência do conteúdo que designa a arquitetura como heterotopia, e não o jogo de oposição ou de contestação, qualitativa ou simbólica, dos outros espaços que este último institui, sua forma, suas rupturas." (DEFERT Em: FOUCAULT, 2013, p.49) (11 $^{1}$

As descrições de Lovecraft são demasiadamente complicadas de entender e conseguirmos tentar visualizar, tanto em seus seres, como com seus locais. A escrita de Lovecraft é repleta de adjetivos e tem uma estrutura que não favorece

20 Pequeno trecho da descrição da cidade de R'lyeh em The Call of Cthulhu "Without knowing what futurism is like, Johansen achieved something very close to it when he spoke of the city; for instead of describing any definite structure or building, he dwells only on broad impressions of vast angles and stone surfaces-surfaces too great to belong to any thing right or proper for this earth, and impious with horrible images and hieroglyphs." (LOVECRAFT, 2011)

21 Pósfacio escrito por Daniel Defert do livro O Corpo Utópico, As Heterotopias (2013). 
tanto a clareza, mas sim coloca o leitor em um processo de imersão em algo que ele entende cada vez menos. Algo que aparenta, inicialmente, combinar com sua ideia fundamental de que o ser-humano realmente não conhece o mundo em que vive, um mundo assustador e monstruoso. Não ousamos afirmar que esse impacto que sua escrita causa é algo que o próprio autor procurava, ou talvez um mero efeito de suas tentativas exageradas de rebuscar suas narrativas.

Embora o recurso de adjetivação tenha sido uma técnica estilísitca recorrente na obra de ambos os autores, sua utilização se dá de formas diferentes ${ }^{22}$. A escrita de Poe é completamente diferente da de Lovecraft nesse quesito. Suas descrições são mais objetivas e compreensíveis. Ao ler um conto de Poe, conseguimos imaginar tudo que o autor nos descreve com precisão.

A forma como Lovecraft leu e se inspirou em Poe não pode ser analisada de modo pontual, apenas no decorrer de deduções baseadas em investigações sobre os autores. Tentamos apontar que houve tal inspiração e que, a julgar pela admiração e pelas semelhanças entre suas obras, sobretudo em Uma Descida no Maelstrom, fora de grande importância e influência para a produção de sua mitologia devido a essa utilização de uma imensidão inevitável e furiosa que torna o humano um pequeno ser em um mundo hostil.

O conto de Poe nos confere uma sensação similar à das histórias de Lovecraft, com um amplo e assombroso poderio do mar engolindo os personagens humanos. O sobrenatural poesco se dá através de um maravilhamento e de uma demonstração da grandiosidade da natureza, enquanto o sobrenatural lovecraftiano se centra em uma premissa mais extra-mundana, com seus seres sobrenaturais oriundos de outras dimesões. Contudo, a insignificância humana diante de uma complexidade e indiferença do univeros prevalece sendo um denominador comum para ambos os autores, sobretudo em Uma Descida no Maelstrom.

\section{Considerações Finais}

Todas as obras são produto de diversos fatores, podendo pensar nos seus autores até como antenas que captam algo que existe no ar e que eles transpõem para suas obras. Sem entrarmos no mérito da precisão ou exagero dessa metáfora da "antena", é necessário destacar aqui que, antes de um escritor ser um produtor de seu texto, ele foi um consumidor de outros textos, muitos dos quais provavelmente influenciaram sua obra.

O teórico Roger Chartier (1996) apresenta o conceito de apropriação que aponta para a pluralidade nas possibilidades interpretativas de leitura. Ou seja, não há uma forma universal de lermos um livro (objeto de estudo de Chartier), mas diferentes maneiras, particulares a cada indivíduo, de compreendê-lo. Segundo o autor, nós nos apropriamos de obras à nossa maneira específica, e cada um possui

22 S. T. Joshi (2014) aponta que: "O mais óbvio aspect estilístico comum a Poe e Lovecraft é o uso dos adjetivos." (p.132) 
uma leitura, uma apropriação pessoal em que todos os fatores possíveis influenciam as diversas formas de consumo de uma obra.

Assim, não podemos analisar a forma como Lovecraft consumiu Poe, mas podemos apontar que houve tal consumo e que, a julgar pela admiração e pelas semelhanças entre suas obras, sobretudo em Uma Descida no Maelstrom, fora de grande importância e influência para a produção de sua mitologia.

Quando falamos em mitologia, devemos sublinhar que Lovecraft não elabora uma religiosidade propriamente, dita e sim uma noção de sobrenatural centrada na figura do monstro. A palavra vem do latim monstrum que significaria algo como "aberração". Todavia, investigando mais a fundo, encontramos o verbo monstrare, que significa "indicar", "apontar", ou, procurando uma palavra mais simples, cotidiana e similar, "mostrar". Então, o monstro seria o "que se mostra", ou, "aberração que se mostra" talvez seja mais próximo de um sentido mais específico.

A figura da monstruosidade exerceu uma função simbólica fundamental. Perturbando os sentidos, especificamente a visão, o monstro foi pensado como uma aberração, uma folia do corpo, introduzindo, como oposição lógica, a crença na necessidade da existência da "normalidade" humana, do corpo lógico." (TUCHERMAN, 1999, p.79)

Partindo da etimologia da palavra monstro, encontramos o ato de se revelar presente nesse ser. No contexto do pensamento medieval, por exemplo, "os monstros são manifestações físicas, palpáveis, corpóreas de atos pecaminosos” (FELINTO; SANTAELLA, 2012, p.85, grifo nosso) ou então materializações do poder ilimitado de Deus (mirabilia). Dessa forma, o aspecto material é altamente essencial e aponta novamente para uma importante relação com a visão, o olho. "O monstro funciona como monstro, em outras palavras, quando é capaz de condensar a maior quantidade possível de atributos produtores de medo para um corpo." (HALBERSTAM, 1995, p.21) (3) $^{23}$

Lovecraft complexifica essa noção de monstruosidade ao trazer um caráter religioso e científico ao panteão teratológico. Ao atribuir o caráter divino aos monstros, trazemos a crença e a fé, presentes na religião, para um plano do tangível, com seres que povoam o mesmo plano material que nós, e que são apresentados através de uma explicação racional e científica. O espantoso em Lovecraft é material, rompe a barreira entre o fantástico e o explicável. A dualidade entre Logos e Mythos, razão e crença, não existe em sua obra.

Poe costumava se concentrar mais em crimes e assassinatos e, em seus contos mais fantasmagóricos, adotava temas clássicos da tradição judaico-cristã

23 "The monster functions as monster, in other words, when it is able to condense as many fear-producing traits as possible into one body." (HALBERSTAM, 1995, p.21) 
de figuras como a Morte, os Espíritos e os locais assombrados. Todavia, em Uma Descida no Maelstrom, Poe parece ter sentido a necessidade de se relacionar com o desconhecido e com a insignificância humana em seu próprio planeta. No entanto, utiliza as águas, e não seres oriundos das profundezas, como seus monstros.

$\mathrm{O}$ que poderia parecer, a princípio, uma diferença entre Lovecraft e Poe nessa ausência do monstro e do aspecto material da divindade torna-se uma semelhança ao percebemos o Maelstrom como uma criatura viva, e a natureza como uma poderosa entidade. Poe descreve seu redemoinho gigante como um dos seres do Cthulhu Mythos, poderoso e imponente como um deus que se encontrava adormecido e foi acordado de seu descanso, repleto de fúria. O Maelstrom representa o desconhecido, o perigoso, o maravilhoso, e nos lembra mais uma vez de nossa insignificância diante do resto do universo.

\section{Referências}

BLOOM, Harold. A Angústia da Influência. Rio de Janeiro: Imago, 2002.

BUHLE, Paul. Dystopia as Utopia: Howard Phillips Lovecraft and the unknown content of american horror literature. Minnesota Review, Durnham, Number 6, Spring 1976 (New Series), pp. 118-131.

CARROLL, Noël. Engaging The Movie Image. Yale University Press, 2003.

CHARTIER, Roger. Práticas da Leitura. São Paulo: Editora Estação Liberdade, 1996.

COLAVITO, Jason. The Cult of Alien Gods: H.P. Lovecraft and Extraterrestrial Pop Culture. New York: Prometheus Books, 2005.

CRARY, Jonathan. Técnicas do Observador: Visão e Modernidade no Século XIX. Rio de Janeiro: Contraponto, 2012.

DÄNIKEN, Erik Von. Eram Deuses Astronautas?. São Paulo: Editora Melhoramentos, 2010.

FELINTO, Erick; SANTAELLA, Lucia. O explorador de abismos: Vilém Flusser e o pós-humanismo. São Paulo: Paulus, 2012.

FERRAZ, Maria Cristina Franco. Homo Deletabilis: corpo, percepção, esquecimento do século XIX ao XXI. Rio de Janeiro: Garanond, 2010.

FOUCAULT, Michel. O Corpo Utópico, As Heterotopias. São Paulo: n-1 Edições, 2013. 
GARCIA, Yuri. Lovecraft e Poe: Ressonâncias nos contos dos mestres do Horror e suas criações de sensações e ambiências. In: COMUNICON - Congresso Internacional em Comunicação e Consumo. São Paulo, 2015.

GUMBRECHT, Hans Ulrich. Reading for the Stimmung? About the Ontology of Literature Today. Boundary 2. Fall 2008, 35(3), p.213-221.

. Produção de Presença: o que o sentido não consegue transmitir. Rio de Janeiro: Contraponto e PUC-Rio, 2010.

GUNNING, Tom. O retrato do corpo humano: a fotografia, os detetives e o primórdio do cinema. In: CHARNEY, Leo; SCHWARTZ, Vanessa R. (orgs.). O Cinema e a Invenção da Vida Moderna. São Paulo: Cosac Naify, 2004.

HALBERSTAM, Judith. Skin Shows: Gothic Horror and the Technology of Monsters. Duke University Press, 1995.

JOSHI, S. T.. A Dreamer and a Visionary: H. P. Lovecraft in his time. Liverpool University Press, 2001.

. A Vida de H. P. Lovecraft. São Paulo: Editora Hedra, 2014.

LOVECRAFT, H. P.. The Complete Works of H. P. Lovecraft. CthulhuChick.com, 2011. (Obtido em domínio público em: http://arkhamarchivist.com/free-complete-lovecraft-ebook-nook-kindle/)

. Supernatural Horror in Literature. 1927. (Obtido em domínio público em: $<$ http://www.hplovecraft.com/writings/texts/essays/shil.aspx>).

. Notes on Writing Weird Fiction. 1933. (Obtido em domínio publico em: $<$ http://www.hplovecraft.com/writings/texts/essays/nwwf.aspx $>$ )

McLUHAN, Herbert Marshall. A Galáxia de Gutenberg: a formação do homem tipográfico. São Paulo: Editora Nacional, 1977.

. Os meios de comunicação como extensões do homem. Cultrix, 2007.

MIGLIORE, Andrew; STRYSIK, John. The Lurker in the Lobby: A guide to the cinema of H. P. Lovecraft. San Franciso: Night Shade Books, 2006.

PAES, José Paulo. Apresentação. In: POE, Edgar Allan. Histórias Extraordinárias. São Paulo: Companhia das Letras, 2008. 
POE, Edgar Allan. Histórias Extraordinárias. São Paulo: Companhia das Letras, 2008.

RANCIÈRE, Jacques. O Destino das Imagens. Rio de Janeiro: Contraponto, 2012.

TODOROV, Tzvetan. Introdução a Literatura Fantástica. Editora Perspectiva, 2012.

TUCHERMAN, Ieda. Breve História do Corpo e de seus Monstros. Lisboa: Editora Vega, 1999.

Filme

THE HAUNTED Palace. Direção: Roger Corman. Produção: Roger Corman;

Ronald Sinclair; Samuel Z. Arkoff e James H. Nicholson. Intérpretes: Vincent Price; Debra Paget; Lon Chaney Jr. E outros. Música: Ronald Stein. Virginia (EUA): American International Pictures (AIP); Alta Vista Productions e La Honda Productions, 1963. (87 min), son., cor, $35 \mathrm{~mm}$. 


\title{
Lovecraft and Poe: resonances in the tales of the masters of horror and its creations of sensations and ambiences
}

\begin{abstract}
The paper aims to present similarities between two great names of horror literature, Edgar Allan Poe and H. P. Lovecraft. The latter kept correspondences and journals of his personal life, in addition to having written essays about the genre, so that we can perceive the idolatry he had for his predecessor recorded in his own words. In this way, we will highlight their similarities and point out a more unknown tale of Poe as possibly one of the greatest inspirations within his work for the development of the narrative and mythology created by his precursor. Among the important points of intersection, we highlight here for a brief analysis: the investigation or report of experience witnessed by the narrator, the atmosphere created for the tale of horror and the danger from the seas and oceans.
\end{abstract}

\section{Keywords}

Lovecraft; Edgar Allan Poe; Horror; Communications; Literature.

\section{Sobre o autor}

Yuri Garcia. Doutor em Comunicação Social na linha de Tecnologias da Comunicação e Cultura do Programa de Pós Graduação em Comunicação da Universidade do Estado do Rio de Janeiro (UERJ). Mestre em Comunicação Social na linha de Tecnologias da Comunicação e Cultura do Programa de Pós Graduação em Comunicação da Universidade do Estado do Rio de Janeiro (UERJ). Possui pós-graduação em Docência do Ensino Superior pela Universidade Cândido Mendes (UCAM-IAVM) e graduação em Comunicação Social - Publicidade e Propaganda pelas Faculdades Integradas Hélio Alonso (FACHA). Coordenador do grupo de pesquisa "Transposições das Narrativas de HQ no Cinema". Também atua no grupo de pesquisa "Culturas Tecnológicas: medialidades, materialidades e temporalidades" coordenado pelo prof. Dr. Erick Felinto. Membro da ACCRJ - Associação de Críticos de Cinema do Rio de Janeiro e curador do Cineclube Silvia Oroz da Universidade Estácio de Sá, campus Tom Jobim. Autor do livro “Drácula: o vampiro camaleônico" (2014), realiza pesquisas sobre transposições cinematográficas de obras literárias, assim como de HQs e videogames. Atualmente é professor da Universidade Estácio de Sá (UNESA) nas graduações em Comunicação Social, Cinema, Produção Audiovisual e Publicidade. yurigpk@hotmail.com 